\title{
NOVO CONSTITUCIONALISMO LATINO AMERICANO E A PARTICIPAÇÃO POPULAR: LIÇÕES PARA O BRASIL
}

\author{
NEW LATIN AMERICAN CONSTITUTIONALISM AND POPULAR \\ PARTICIPATION: LESSONS FOR BRAZIL
}

Thiago Henrique Costa Silva ${ }^{1}$

Aceito em 05/09/2020

Bruna Daniele de Souza Pereira ${ }^{2}$

\section{RESUMO}

Este trabalho tem o objetivo de compreender o constitucionalismo latino-americano, que almeja um Estado com maior participação popular e ressignificação do papel dos governantes, alçando o povo ao seu lugar de soberania. A análise foi feita a partir do método comparativo funcional, utilizando-se de levantamentos bibliográficos. Realizou-se a comparação entre as realidades dos países que adotam o modelo e a do Brasil, com foco nos aspectos sociais e políticos, delineando as lições que podem ser aprendidas com as experiências dos países vizinhos. Do estudo, notou-se que a constituição brasileira avançou no sentido de garantir direitos e o exercício da democracia de maneira direta, contudo a participação popular ainda é tímida, quando comparada aos países vizinhos, sobretudo no que tange ao pluralismo. A desigualdade social, ancorada em uma hegemonia política e econômica de uma pequena parcela da população, associada à corrupção sistêmica, apresentam-se como entraves para a ampliação democrática.

Palavras-chave: Novo constitucionalismo latino-americano. Cidadania. Participação Popular. Pluralismo.

\section{ABSTRACT}

This paper aims to understand Latin American constitutionalism, which seeks a state with greater popular participation and new signification of the role of rulers, raising the people to their place of sovereignty. The analysis used the comparative method, based on bibliographical surveys. The comparation was made with the Brazilian reality, especially regarding social and political aspects, outlining the lessons that can be learned from the experiences of neighboring countries. After the study, it was noted that the Brazilian constitution has advanced to guarantee rights and the direct exercise of democracy, however, popular participation is shy compared to neighboring countries, especially with regard to pluralism. Social inequality, anchored in a political and economic hegemony of a small portion of the population, associated with systemic corruption, are obstacles to democratic expansion.

Keywords: New Latin American constitutionalism. Citizenship. Popular participation. Pluralism.

\footnotetext{
${ }^{1}$ Doutorando em Agronegócio pela Universidade Federal de Goiás (UFG). Mestre em Direito Agrário pela UFG. Graduado em Direito pela UFG. Graduando em Economia pelo Instituo de Ensino Superior de Brasília (IESB). Perito Criminal da SPTC-GO. Professor de Direito Constitucional e Pesquisador do Centro Universitário Alves Faria (UNIALFA) e do Centro Universitário Alfredo Nasser (UNIFAN).

${ }^{2}$ Graduada em Direito pelo Centro Universitário Alves Faria (UNIALFA). Advogada.
} 


\section{INTRODUÇÃO}

O novo constitucionalismo latino-americano surge de movimentos sociais que buscam estruturar a sociedade de acordo com o interesse coletivo, por isso é considerado um modelo que amplia a participação popular, partindo da sociedade para os poderes públicos.

No que tange as características iniciais do novo modelo constitucional, pode-se enunciar que é a concretização de um desejo da sociedade em delimitar a ação governamental para garantir um Estado Democrático de Direito através da participação popular, com o fim de promover mudanças em diversos setores, inclusive, no âmbito da política.

Com relação ao Brasil, o país tem enfrentado um período de instabilidade econômica e vivenciado diversas crises políticas, que demonstram as insatisfações da população com seus representantes.

As insatisfações populares, que culminaram com a renovação significativa nos quadros políticos do país após as eleições de 2018, demonstram a necessidade de consolidar uma democracia mais participativa, evidenciando, assim, a necessidade de se (re)pensar o modelo institucional. Tal tarefa pode ser realizada por meio das lições advindas do novo constitucionalismo latino-americano.

Dessa forma, comparativamente, surge a necessidade de compreender o constitucionalismo latino-americano, como um modelo que amplia a participação cidadã e promove justiça social, relacionando-o ao constitucionalismo brasileiro.

Parte-se da ideia de que a agenda desse movimento é lastreada pela urgência de (re)construção do Estado, impondo um olhar crítico para as suas dificuldades, sobretudo de ordem prática. Logo, o artigo busca enfrentar o seguinte problema: há avanços no novo constitucionalismo latino-americano que podem agregar características para a evolução do constitucionalismo brasileiro?

Para tanto, haverá uma pesquisa exploratória, consubstanciada em levantamento bibliográfico, para delinear as características deste novo constitucionalismo. Ainda, será adotado o método comparativo funcional, com a intenção de explicitar as semelhanças e diferenças entre os diversos modelos latino-americanos e a realidade brasileira, partindo da hipótese de que há a possibilidade de considerá-lo como inspiração para modificar a organização, sobretudo política, do Estado brasileiro, especialmente diante das crises institucionais vivenciadas.

Dessa forma, em um primeiro momento, busca-se contextualizar o processo de formação do movimento constitucional latino-americano. Posteriormente, delineia-se algumas características do novo constitucionalismo para, em seguida, compreender a realidade desse novo 
modelo, a partir da análise da questão agrária dos países e da democracia participativa, elementos escolhidos para serem estudados pela importância dos temas dentro da conjuntura política dos países que seguem a sua lógica.

Por fim, é realizada uma análise da realidade brasileira, comparando a questão fundiária, a forma de democracia participativa e a necessidade de avanços do modelo constitucional, sobretudo para garantir a soberania popular. Assim, destacam-se as premissas teóricas que o novo constitucionalismo apresenta ao constitucionalismo do Brasil.

\section{CONTEXTUALIZANDO O NOVO CONSTITUCIONALISMO LATINO- AMERICANO}

Surge na América Latina, no final da década de 80, uma conjuntura política e institucional que veio para atender ao chamado da sociedade diante de suas necessidades: o fenômeno político, social e jurídico, denominado novo constitucionalismo latino-americano.

Esse movimento tem o intuito de limitar o poder estatal e fortalecer o poder que pertence ao povo, ao passo que busca a efetividade da soberania popular, sendo essa, por sua vez, concretizada através do atendimento das reivindicações do povo pela busca de condições melhores de vida que promovam um bem-estar coletivo, o bem viver, integrando o homem e a natureza.

Além disso, pelo fato de o povo ser titular do poder soberano, esse novo modelo preza pela participação da sociedade nas decisões políticas e, inclusive, pela proteção das minorias e pelo respeito às diversidades culturais. As ideais do constitucionalismo latino foram ao encontro das palavras de Kelsen (2000) sobre a importância do povo para a organização de um Estado. Segundo o autor, somente pode-se dizer que o povo é constituinte do poder quando ele é capaz de influenciar a ordem jurídica e participar efetivamente da criação estatal.

Fruto de uma grande luta e resistência diante das diversas imposições políticas neoliberais, que constantemente provocam ondas de austeridade pelo continente americano, reduzindo os programas sociais do governo, minimizando os direitos trabalhistas e previdenciários, agravando, por conseguinte, as desigualdades sociais e a insatisfação popular (BASTOS, 2015), o novo constitucionalismo latino-americano se consolida, configurando instrumento de (re)existência no sul americano. Através dos movimentos sociais, a sociedade começou a reagir diante de tais imposições, lutando, reivindicando e buscando por seus direitos (PETRY, 2008). 
Desse modo, a luta da sociedade pela concretização dos direitos e garantias fundamentais, o reconhecimento e respeito pela diversidade cultural, são algumas das características perseguidas pelos países latinos. O povo (re)assume o seu papel de protagonista em uma democracia cada vez mais participativa (FREITAS; WOLKMER, 2017).

Algumas características do modelo se destacam, a exemplo do anticolonialismo, do pluralismo, do pluranacionalismo, da multiculturalidade e da refundação do Estado.

O anticolonianismo, segundo Chauvin (2015), consiste em um misto de sentimentos, reflexões, posturas e atitudes que levam os indivíduos a questionar as premissas coloniais que determinam o funcionamento do Estado, do território e do modo como os povos se organizam. Assim, os povos buscam uma liberdade de escolha, de pensamento, de se autogovernarem, de escolherem seus partidos políticos e seus governantes, em consonância com a composição da sociedade, fugindo das ideias coloniais e oligárquicas que influenciaram a criação do Estado e de suas instituições. É a construção de um modelo próprio e representativo.

Por sua vez, o pluralismo político não está relacionado às diversidades de partidos políticos, mas sim à diversidade de opiniões entre grupos distintos da população que participam da democracia do país. Em um contexto mais amplo, quando se reconhece as múltiplas práticas jurídicas no mesmo espaço político, mediante as existências culturais de cada grupo, tem-se um país plural (WOLKMER, 2001).

Já o pluralismo jurídico pode ser conceituado pela existência de mais de um ordenamento jurídico dentro de um Estado. Wolkmer (2001) destaca que o pluralismo jurídico é importante por ter como foco, alcançar a justiça social, de modo a chegar às camadas mais pobres e, se constituir como base de poder, de modo a apresentar alternativa a lógica do direito dominante, reconhecendo as peculiaridades dos sujeitos que integram o Estado.

Em uma relação complementar ao pluralismo, o Estado plurinacional é caracterizado pela democracia participativa, apta a reconhecer as diversidades de nacionalidade, o que implica na ideia de um mesmo território regido por uma Constituição que reconhece um gama de nações, abandonando, assim, o velho paradigma do Estado de nação única (FREITAS; WOLKMER, 2017, p.620).

Enquanto a plurinacionalidade resgata e reconhece outras formas de organizações evidenciadas no próprio Estado, ampliando o poder político aos membros de outros povos (SANTOS, 2012), a multiculturalidade é caracterizada pela existência de várias culturas dentro de um Estado ou país. O multiculturalismo aparece como um princípio étnico, que orienta a ação dos grupos culturalmente dominados, aos quais foi negado o direito de preservarem suas características culturais (VITORINO, 2016). 
Dessa forma, o novo constitucionalismo latino-americano se consolida como um movimento que se iniciou nas ruas, por iniciativa da sociedade, em decorrência das diversas insatisfações com o governo, com a estrutura política e com as desigualdades sociais e, fundamentado na necessidade de garantir a soberania popular e o exercício democrático, refunda o Estado.

Os avanços desse movimento nos países latinos no decorrer do século XXI mudam os rumos das sociedades, que veem seus anseios melhores expressados nos textos constitucionais. Já na primeira década do presente século, com as revoluções democráticas da Bolívia e do Equador, estabelecendo poderes constituintes legítimos, fundam-se novos Estados, capazes de superar a brutalidade neoliberal nas Américas (MAGALHÃES, 2012).

Para Magalhães (2016, p. 65), o novo constitucionalismo aplicado na Bolívia e Equador possui uma "alternativa de superação das engrenagens uniformizadoras do Estado moderno", que opera como um novo sistema que abandona a ideia de ter o Estado como monopolizador do poder, evidenciando o povo como verdadeiro ator do poder constituinte.

A Constituição Colombiana, apesar de não ser destacada como uma das novas constituições latino-americanas, é tida pela maioria da doutrina como um marco inicial desse movimento, vez que abarca a participação popular na convocação de uma assembleia constituinte (SILVA; GONÇALVES NETO, 2017).

Na Constituição Colombiana, datada de 1991, o povo é reconhecido, podendo exercer direitos políticos de forma mais ampla, para além de votar, participando ativamente das questões políticas. Os arts. 152 e 154, por exemplo, são bem claros ao garantir a esses cidadãos a livre intervenção em processos legislativos, ou seja, há a previsão de que por iniciativa popular ocorra a criação de leis ou mesmo a participação em sua elaboração.

Já na Venezuela, logo depois de eleito em 1999, através da assembleia nacional constituinte, Hugo Chávez cumpre com sua promessa eleitoral, realizando o chamamento de um plebiscito, respeitando a Constituição da Venezuela, que já anunciava em seu preâmbulo uma recriação da república com o intuito de estabelecer uma sociedade mais participativa e democrática.

Além disso, a Constituição da Venezuela dá ênfase às questões pluricultural e ao pluralismo. Os povos e os governadores participam da refundação constitucional, pois, assim como o povo exerce a democracia de forma participativa, o governo também deve exercer de forma igualitária (SOUZA, 2016, p. 388).

Outrossim, outro elemento presente na Constituição da Venezuela são as revogabilidades de mandatos. Em que pese o sistema político ser baseado em mandatos representativos, os 
mesmos são consequentemente revogáveis, segundo o art. 72, após ser submetido ao domínio escolha - popular.

Há de se ressaltar, ainda, que o art. 136 prevê a redistribuição dos poderes em poder legislativo, executivo e judiciário, mas inclui o poder do cidadão, previsto no art. 274. Há também o poder eleitoral, previsto pelo art. 294, em que são estabelecidas as funções públicas, sendo exercido pelo conselho nacional eleitoral. A Constituição da Venezuela ainda regula o direito de voto aos estrangeiros, ao passo que amplia consideravelmente a cidadania de tais indivíduos (AGUADO; ALMEIDA, 2017, p. 231).

$\mathrm{O}$ art. 347 da constituição estabelece que o povo possui a prerrogativa de provocar uma assembleia constituinte, podendo alterar ou criar a qualquer tempo um novo ordenamento jurídico para o Estado.

Na Constituição Equatoriana, de 2008, a participação popular na política é elencada pelo art. 56, em que se prevê a jurisdição indígena própria, claro exemplo de plurinacionalismo. Segundo Silva e Gonçalves Neto (2017, p. 47), a Constituição Equatoriana, em seu art. $1^{\circ}$, estabelece que o povo é que detém da legitimidade, podendo exercê-la de forma direita ou de forma indireta.

Diretamente, há a presença da participação popular na democracia do Estado. Conforme o art. 195, o povo deve participar do desenvolvimento e controle da política. E, indiretamente, há a democracia representativa, em que o povo pode escolher seus representantes. Ainda assim, é possibilitado um controle direto por parte do povo, que pode solicitar a revogação do mandato com a anuência de $15 \%$ dos eleitores. Quando se tratar de presidente, a solicitação deve ser feita com mínimo $10 \%$, representando a vontade popular.

Outra novidade trazida pela Constituição Equatoriana diz respeito ao art. 71, que reconhece o Direito à natureza. O texto constitucional passa a mencionar a natureza como mãe terra, deixando de lado a visão clássica que tem a natureza como sinônimo de recursos naturais. A natureza para a ser tratada como um sujeito capaz de usufruir de seus direitos, devendo, portanto, ser resguardada.

Na Bolívia, discutir uma nova Constituição foi a opção para reconhecer a legitimidade dos diversos sujeitos que compõem o Estado, sobretudo os indígenas, comumente deixados à margem do ordenamento jurídico. O Estado boliviano é refundado com base no pluralismo político constitucional. A valorização cultural e étnica, o respeito a diversidades e à participação popular eleva a Constituição Boliviana a uma realidade de maior democracia.

Freitas e Wolkmer (2017, p. 611) esclarecem que "a Constituição Boliviana de 2009 nasceu desse modo, com o compromisso do pluralismo político-institucional, da justiça social, e 
da soberania popular, na defesa de uma igualdade democrática." Em seu art. $7^{\circ}$, por exemplo, é ressaltado os moldes da soberania popular exercida diretamente pelo povo.

\section{NOVO CONSTITUCIONALISMO LATINO AMERICANO NA PRÁTICA}

O novo constitucionalismo restaura a soberania popular e "investe em vários mecanismos de democracia direta, participativa e comunitária como forma de reforço e garantia constitucional dos direitos fundamentais inseridos na constituição das regiões" (FREITAS; WOLKMER, 2017, p. 601). Para Cadermotori e Costa (2013), no novo constitucionalismo latino-americano, o conteúdo da Constituição deve ser coerente com sua fundamentação democrática, ou seja, deve haver a direta participação política que limite os poderes políticos de modo a priorizar os direitos dos cidadãos.

Além de controlar e limitar o poder estatal para aumentar os direitos e participações da sociedade, também é trazida, por esse novo modelo constitucional, a busca pela prevenção da desigualdade VICIANO; MARTINEZ, 2010). Nesse sentido, entender a configuração da questão agrária, o funcionamento da democracia participativa e o pluralismo jurisdicional são caminhos para avaliar o novo constitucionalismo.

\subsection{A questão agrária nos países latinos}

A história pela luta da terra e revolução agrária na América Latina ocorre de forma intensa e conflituosa. No início do século XX, as revoluções, tais como a Mexicana, já abordavam questões referentes a luta pela terra e pela revolução agrária. Por sua vez, a revolução agrária cubana influenciou a revolução de diversos países latino-americano, tais como Venezuela e Bolívia, conforme ressalta Fernandes (2011).

Logo, com o intuito de construir uma sociedade mais justa e democrática nos países latinos, a reforma agrária é adotada, reconfigurando o cenário político latino-americano, especialmente porque por trás da reforma agrária existe uma luta anticolonial, pois a terra, a posse e os recursos da terra estão interligados a uma questão hegemônica e de concentração de poder na mão de poucos.

Explicando tal fato, na segunda metade do século XX, com a mecanização da agricultura, o solo passou a ser associado à produtividade e geração de riquezas, servindo como recurso para 
ampliação do chamado modelo capitalista (RAMOS, 2001). A estrutura fundiária da América Latina foi aliada aos grupos que controlavam o capital, especialmente por serem diretamente correlacionados com o desenvolvimento da agricultura, impulsionados pela formulação de políticas agrícolas que aumentaram a concentração de terra renda e ampliaram as desigualdades sociais.

Por exemplo, em países como Venezuela e México, a metade da população rural vive em situações de pobreza extrema e em terras pouco férteis (LEITE; ÁVILA, 2007). Criticando tal realidade, Guillermo O’Donnell (1998) considera que o limite democrático latino-americano se encontra na condição difusa de pobreza extrema em que convivem as sociedades, a qual mantém grande parte da população em situação inferior de cidadania.

Todavia, a questão agrária nos países latinos ganha destaque em alguns países, em especial no final do século XX e no início do século XXI, com as mudanças promovidas pelo novo constitucionalismo, para que, através da redistribuição de terras, as desigualdades sociais e a concentração de renda fossem amenizadas.

$\mathrm{Na}$ Venezuela, por exemplo, o principal foco da reforma agrária foi fazer com que deixasse de existir a propriedade sem uso, o latifúndio. Assim, o caminho foi a realização de uma série de fiscalizações e intervenções estatais. Todavia, tais fiscalizações tornaram-se de difícil sustentação, quando o povo passou a acusar o Estado de estar invadindo propriedades que não lhes pertencia (LEITE; ÁVILA, 2007).

A situação colombiana foi semelhante, pois grande parte da população vivia na zona rural, mas a terra era concentrada nas mãos daqueles que a ganharam por meios violentos e com a força do capital. Assim, a intenção da reforma agrária seria valorizar as comunidades camponesas, mas, isso não ocorreu com intensidade porque houve uma valorização das grandes propriedades no processo produtivo, processo defendido por embates pelo direito de propriedade (LEITE; ÁVILA, 2007).

Outrossim, no Equador, a reforma agrária surgiu com a intenção de redistribuir as terras aos povos e as comunidades, além de querer melhorar a produção, e, essencialmente, respeitar a propriedade que, de fato, obteve resultados positivos, com destaque para o avanço dos mecanismos de proteção da natureza e no respeito aos povos originários (LEITE; ÁVILA, 2007).

Deve-se lembrar que a questão agrária é tema antigo e decorrente do movimento de ocupação e de políticas públicas sucessivas no continente americano, contudo, a terra e sua concentração é elemento central para combater a desigualdade e as reformas que promovam mudanças estruturais, ainda que contem com a desaprovação dos grupos hegemônicos que detêm as propriedades, são imperiosas para que haja uma verdadeira refundação do Estado. 


\subsection{A (in)efetiva democracia participativa}

Inicialmente, insta salientar que a democracia participativa é o meio que possibilita ao povo o exercício de seu poder. E esse poder é exercido através das participações em todos os atos da sociedade, inclusive na tomada de decisões (LAMBERTUCCI, 2009).

O modelo latino-americano avança nesse conceito, pois quer entregar ao povo uma democracia ativa e direta, todavia deve ser analisado com cuidado. Na Bolívia, por exemplo, há três formas de participação democrática, sendo estas a democracia direta, participativa, representativa e comunitária. A democracia participativa é exercida através do consenso democrático, ao passo em que há diálogo igualitário entre todos os componentes da sociedade, inclusive entre o vencedor e vencido (MAGALHÃES, 2012). Já as demais ocorrem por meio das eleições e do voto.

No novo constitucionalismo, há uma ressignificação dos direitos fundamentais presente na sociedade através da legitimidade e participação popular. Isso porque o povo deve intervir em qualquer alteração constitucional, de modo que fiquem cientes de tudo o que for feito pela assembleia constituinte. Sendo assim, o processo constitucional preza, acima de tudo, a participação popular (PASTOR, 2012).

Essa democracia tende a ser plural, uma vez que os diferentes povos, "ao tomarem consciência do seu estado de exclusão da esfera política e social no Estado, (...) buscaram de forma mais organizada, uma participação inclusiva nos assuntos públicos" (FREITAS; WOLKMER, 2017, p. 609).

Uma crítica à prática dessa democracia participativa recai sobre a corrente radical que defendia a implantação de uma sociedade autogovernada. Nos termos de Barbosa (2015, p. 53), “o radicalismo propôs um estreitamento nas relações entre representantes e representados”, que teria gerado uma desordem social e até mesmo um caos institucional, com a instalação de governos populistas e autoritários.

Asseverando a crítica, Gargarella (2010), aborda que, ao mesmo tempo em que as Constituições preveem a participação popular, conferiram mais poderes ao Executivo e ao Estado, reverberando na democracia e nos mecanismos dos poderes constituídos nesses países. Com isso, segundo o autor, o ideal da democracia participativa é ampliar o poder do povo, controlando o poder do Estado. 


\subsection{O funcionamento do judiciário plural}

Para Santos (2010), “a plurinacionalidade é uma demanda por reconhecimento de outro conceito de nação, a nação concebida como pertença comum a uma etnia, cultura ou religião".

Vasconcelos (2014) ressalta que, na visão deste novo constitucionalismo, é atribuído ao Direito a função de transformar a sociedade, possibilitando a concretização dos projetos da sociedade, a serem realizados pelo conjunto das instituições estatais, requerendo a reconstrução da jurisdição, tendo em vista que os juízes da democracia contemporânea devem interagir com a sociedade e os seus anseios. Ademais, o Judiciário plural faz com que a justiça possua uma função transformadora, interligada a nova realidade da sociedade, em que os juízes passam a atuar promovendo a integração social.

Nesse sentido, a utilização de informações culturais e étnicas, levando em conta que, de fato, existem culturas diversas e nações distintas, tais como as indígenas, é expressão de promoção da isonomia constitucional (WOLKMER, 2011).

Mas, ao mesmo tempo que busca promover o pluralismo e a inclusão social, o Poder Judiciário do modelo latino-americano passa por um descrédito social, mediante a incapacidade de assegurar uma forma satisfatória a efetividade dos direitos, sobretudo para os grupos menos favorecidos (VASCONCELOS, 2014). Nesse sentido, apesar dos avanços, pela novidade de sua utilização, o pluralismo nos judiciários latinos deve ser analisado de maneira pormenorizada, o que não é o objetivo desta pesquisa.

\section{CONTRIBUIÇÕES DO NOVO CONSTITUCIONALISMO PARA O ORDENAMENTO JURÍDICO BRASILEIRO: UM PAÍS DE CONFLITOS}

Dos tópicos anteriores, pode-se inferir que o novo constitucionalismo latino-americano é proveniente de lutas e reinvindicações populares por um novo modelo de organização do Estado e do Direito, e assim visa reconhecer e ampliar os direitos fundamentais de determinada sociedade (CADEMARTORI; MIRANDA, 2016).

Logo, nesse novo modelo constitucional, há uma ressignificação de conceitos como a legitimidade, a participação popular, e os direitos fundamentais, em especial no que tange a pluralidade de sujeitos e culturas existentes (AGUADO; ALMEIDA, 2017)

Wolkmer (2012) ressalta que na Constituição dos países que adotaram esse novo modelo 
constitucional, houve mudanças significativas no que tange ao avanço democrático em decorrência da participação popular. Tal modelo guarda semelhanças com aquele adotado pela constituição do Brasil, sobretudo na priorização da participação popular após períodos de reivindicações sociais.

Ainda no período da ditadura militar, no decorrer da décadas de 1970 e 1980, foram deflagradas várias lutas sociais pela redemocratização do país (RONCHI; WOLKMER, 2016), até que foi promulgada a Constituição Federal de 1988, trazendo diversas novidades, dentre elas uma grande amplitude dos direitos fundamentais, tais como aqueles relacionados às questões ambientais, dos idosos, das crianças, dos adolescentes, dos povos comunitários e dos indígenas.

Entretanto, não basta ter uma norma que garanta direitos, se eles não forem efetivados. Somente com a aplicabilidade e eficácia dos direitos é que se poderá falar em evolução constitucional. Assim, os próximos tópicos abordarão a questão agrária, o processo democrático brasileiro, a corrupção, a participação popular e a necessidade de avanços, que podem passar pelas lições trazidas pelo novo constitucionalismo latino-americano.

\subsection{A questão agrária no Brasil}

Paula e Gediel (2017) elucidam que a estrutura agrária brasileira é caracterizada pela concentração da propriedade de terra, em um processo histórico de apropriações indevidas e desregulamentação fundiária.

Não diferente dos vizinhos latinos, a desigualdade no campo é premissa antiga, iniciada no período colonial, quando a posse e a propriedade privada dos portugueses usurparam o exercício dos territórios indígenas e os expulsaram de suas terras. Após o período colonial de desterritorialização, os latifúndios foram, aos poucos, se consolidando, tornando-se sinônimos de poder e riquezas.

Gradativamente, a extensão da propriedade da terra foi sendo ampliada, em um sistema de posses desreguladas, operando uma supressão dos direitos dos camponeses, aqueles que tinham na terra um modo de vida e de reprodução familiar, sendo que o latifúndio, expressão desse cenário excludente, se fundaria em um modelo de produção voltado ao lucro e produção de produtos para exportação (TÁRREGA; MAIA; FERREIRA, 2012). Assim, hodiernamente, enquanto uns possuem muitas terras, outros possuem poucas, ou até mesmo nenhuma.

Há de se ressaltar que, sobre tal aspecto, os países latinos do novo constitucionalismo englobam na proposta política uma revisão de seus territórios, tendo como pauta importante a 
reforma agrária e, consequentemente, a luta por reforma agrária. A distribuição de terra de maneira igualitária seria capaz de gerar positivamente um aprendizado, além dos direitos sobre a propriedade, enxergando o sujeito e não apenas o que se está positivado, indo ao encontro dos interesses públicos e de encontro à lógica latifundiária (LEITE, 2000).

Apesar de prevista constitucionalmente, a reforma agrária no Brasil é vista como um tabu político e até mesmo desnecessária por parte de alguns pesquisadores (BUAINAIN et al, 2013), carecendo, portanto, de efetividade. Assim, a despeito de existir enquanto direito, inexiste enquanto fato, permanecendo a proteção máxima do direito da propriedade e do sistema produtivo fundamentado na concentração de renda e de terra, fator asseverado nos últimos anos, desde o governo Temer, com investidas da Frente Parlamentar Agropecuária para a proteção da propriedade como valor sagrado e na relativização da função social.

\subsection{A participação democrática no Brasil}

Teoricamente, a democracia participativa é caracterizada pela existência da pluralidade de opiniões públicas que possuem o condão de limitar o poder estatal e, nas palavras de Barbosa (2015), pressupõe a participação cidadã, na qual a tomada de decisões passa pela intervenção dos cidadãos, ou seja, é uma recolocação do povo no seu lugar soberano. Nesse sentido, o próprio povo possuiria todos os mecanismos para participar ativamente das decisões políticas do Estado. Em outros termos, a democracia participativa possui a finalidade de regenerar a democracia representativa, aquela exercida por representantes do povo.

No Brasil, a democracia participativa é elencada pelo art. $1^{\circ}$, parágrafo único da Constituição Federal de 1988, em que se afirma que "todo o poder emana do povo, que o exerce por meio de representantes eleitos ou diretamente".

Não diferente do caso brasileiro, os Estados que desenvolvem o modelo constitucionalista latino-americano preveem mecanismos de democracia participativa e representativa, sendo que a diferença é a existência de avanços na participação direta, tal qual previsão da iniciativa popular simplificada para emenda constitucional, assegurada pelas Constituições da Bolívia, do Equador e da Venezuela (PASTOR; DALMAU, 2010).

Alguns mecanismos participativos são elencados na Constituição Federal de 1988, no inciso terceiro do art. 14 e no parágrafo segundo do art. 61, que dispõem sobre a iniciativa popular para propositura de projeto de lei, além de prever a possibilidade de plebiscito e referendo. Contudo, apesar de serem previstos, não modificam a realidade social e jurídica brasileira (BARBOSA, 
2015).

Uma outra forma de participação interessante, construída pelos países latinos, é a possibilidade de revogação popular de mandato do chefe do executivo. A Constituição da Venezuela e a Constituição Equatoriana de 2008, por exemplo, passaram a ter previsão de que, quando o povo assim decidisse, poderia revogar o cargo, antes mesmo de terminar o mandato (PASTOR; DALMAU, 2010), enquanto, no Brasil, o povo só pode modificar, diretamente, a titularidade do chefe do executivo na próxima eleição ou, indiretamente, mediante um processo burocrático de impeachment ${ }^{3}$.

\section{CONSIDERAÇÕES FINAIS}

O novo constitucionalismo latino-americano, que ganha forma no final da década de 80, é, antes de ser um modelo teórico, um movimento social que amplia a participação popular, estrutura a sociedade de acordo com os interesses coletivos e limita o poder estatal. Em outros termos, os poderes do Estado são limitados em detrimento do povo, a fim de garantir um Estado Democrático de Direito.

A luta da sociedade latina, que possibilitou o surgimento desse novo movimento constitucional, decorre, principalmente, da necessidade de concretização dos direitos fundamentais e de reconhecimento das diversas culturas. No final do século XX, tal movimento começa a se consolidar na Colômbia e, com maior efetividade, na Bolívia. Em ambos os países, houve uma revolução pacífica e democrática, ao passo que fundaram um novo Estado que evidencia e consolida a soberania popular. Nesse sentido, no Equador, a participação popular é ampliada e o povo é colocado como um quarto poder, responsável por participar do desenvolvimento e do controle de políticas públicas.

Sendo assim, por ser o novo constitucionalismo latino-americano um movimento que se iniciou por meio da vontade popular, em decorrência de diversas insatisfações com a política e o governo, caminhando, somente depois, para a teorização, novos elementos, como o pluralismo político e jurídico, aparecem como avanços a serem estudados.

Analisando a teoria e também o escopo prático, percebe-se que o povo é quem estabelece

\footnotetext{
${ }^{3}$ Impeachment, de origem no latim impedimentum, significa impedir, proibir de permanecer. No Brasil, o tema passou a ser retratado a partir da Constituição Imperial de 1824, sofrendo restrições nas constituições de 1937 e 1967, por seus caráteres autoritários, sendo retomado com maior efetividade em 1988, no artigo 85 do texto constitucional, configurando um processo político-criminal em que se apura crimes de responsabilidade do Presidente da República.
} 
condições para que ocorra uma refundação estatal, constitucional e participativa, mas que ainda há limites entre o discurso e a realidade. Um exemplo é a grande dificuldade de se realizar a reforma agrária nos países latinos, em razão do grande poder econômico e político dos detentores da terra, situação bem semelhante, mas ainda mais inefetiva, quando a realidade brasileira é observada.

Já no que envolve a participação democrática, houve um estreitamento nas relações entre os representantes e representados, contudo, ao mesmo tempo que concediam poderes ao povo, também concediam poderes ao Estado, de forma que alguns regimes autoritários foram legitimados. Ainda assim, grandes contribuições podem ser extraídas das experiências latinas. No sistema equatoriano, por exemplo, há possibilidade de revogação de mandato e a previsão de que o referendo seja utilizado por iniciativa do povo, e não só por parte de seus representantes eleitos.

Quanto à participação democrática no Brasil, há de se destacar que existem previsões no seu texto constitucional, entretanto, é comum o estabelecimento de políticas públicas que não coadunam com o interesse do povo.

Em meio às crises políticas dos últimos anos, a corrupção assola o Brasil, sendo que a democracia e o seu exercício, são postos em xeque. Assim é inegável a necessidade de pesquisas de direito comparado, sobretudo com os vizinhos latino-americanos, que guardam realidades semelhantes, com o fim de estabelecer novas formas de participação popular, levantando não só os pontos positivos, como também os pontos negativos do modelo, aproveitando as lições para avançar no processo democrático brasileiro.

Sabendo da complexidade do tema, este artigo não possui a pretensão de esgotá-lo, mas de levantar possibilidades para pesquisas futuras, que busquem compreender a realidade de forma crítica e voltadas às contribuições para a sua transformação.

\section{REFERÊNCIAS}

AGUADO, Juventino de Castro; ALMEIDA, Angelo. O novo constitucionalismo latinoamericano: possibilidades de uma constitucionalização simbólica. Revista de Artigos do $\mathbf{1}^{\circ}$ Simpósio sobre Constitucionalismo, Democracia e Estado de Direito, v.1, n.1, jan, 2017.

BARBOSA, Maria Lúcia. Democracia direta e participativa: um diálogo entre a democracia no Brasil e o novo constitucionalismo latino americano. Tese (doutorado) - Universidade Federal de Pernambuco Centro de Ciências Jurídicas Faculdade de Direito do Recife Programa de PósGraduação em Direito, Recife, 2015.

BASTOS, Pedro Paulo Zaluth. Austeridade para quem? A crise global do capitalismo 
neoliberal e as alternativas no Brasil. Texto para Discussão. IE/Unicamp, Campinas, n. 257, ago. 2015.

BUAINAIN, Antônio Márcio; ALVES, Eliseu; SILVEIRA, José Maria da; NAVARRO, Zander. Sete teses sobre o mundo rural brasileiro. Revista de Política Agrícola. Ano 22, n. 2, p. $105-$ 121, abr./mai./jun./ 2013.

CADEMARTORI, Sergio Urquhart; MIRANDA, José Alberto Antunes de. Democracia, Exteriores: o papel do Direito e da Cidadania no Contexto do Novo Constitucionalismo LatinoAmericano. Sequência (Florianópolis), n.72, abr. 2016.

CHAUVIN, Jean Pierre. Anticolonialismo. Revista de Estudos de Cultura, n.3, set./dez., 2015.

FERNANDES, David Souza. "Sem revolução não há nação": a nação cubana nos escritos de Fidel Castro (1953-1959). Temporalidades-Revista Discente-UFMG, v.3, n.2, ago./dez., 2011.

FREITAS, Raquel Coelho; WOLKMER, Antônio Carlos. O impacto do novo constitucionalismo nos processos de construção da democracia na América Latina. Revista da Faculdade de Direito da UFMG,Belo Horizonte,n.70, p. 595-631, jan./jun., 2017.

GARGARELLA, Roberto. Apuntes sobre el constitucionalismo latino americano del siglo XIX. Una Miranda histórica.Revista del instituto de Ciencias jurídicas de Puebla AC (IUS), v.4, n.95, 2010.

KELSEN, Hans. A Democracia. Tradução: Ivone Castilho Beneditte et al. São Paulo: Martins Fontes, 2000.

LAMBERTUCCI, Antonio Roberto. A participação social no governo Lula. São Paulo: Cortez, 2009.

LEITE, Sérgio Pereira; ÁVILA, Rodrigo Vieira. Reforma agrária e desenvolvimento na América Latina: rompendo com o reducionismo das abordagens economicistas. Revista de Economia e Sociologia Rural, Brasília, v.45, n.3, jul./set., 2007.

LEITE, Sérgio. Impactos regionais da reforma agrária no Brasil: aspectos políticos, econômicos e sociais.In: LEITE, Sérgio Pereira (ed.) Reforma Agrária e Desenvolvimento Sustentável. Brasília: Paralelo, 2000.

MAGALHÃES, José Luiz Quadros de. A Constituição de 1988 e a construção de um novo constitucionalismo democrático na América latina: Direito à adversidade individual e coletiva e a superação de uma teoria da constituição moderna. Revista Brasileira de Direito Constitucional Aplicado, n.1, jan./jun. 2016.

MAGALHÃES, José Luiz Quadros de. Estado plurinacional e direito internacional. Curitiba: Juruá, 2012.

O’DONNELL, Guillermo. Poliarquias e a (in)efetividade da lei na América Latina. Novos Estudos, CEBRAP, n. 51, jul. 1998.

PASTOR, Roberto Viciano. Fundamento Teoricodelnuevo constitucionalismo 
latinoamericano: estudios sobre elnuevo constitucionalismo latinoamericano. Valência: Tirantlo Blanch, 2012.

PASTOR, Roberto Viciano; DALMAU, Rúben Martinez. Presentación. Aspectos generales del nuevo constitucionalismo latinoamericano. In: Corte Constitucional de Ecuador para el período de transición. El Nuevo constitucionalismo en America Latina. Quito: Corte Constitucional delEcuador, 2010.

PAULA, Roberto de; GEDIEL, José Antônio Peres. Questão agrária: entraves jurídicos processuais recorrentes e desigualdade social. Revista Direito e Práxis, Rio de Janeiro, 2017.

PETRY, Almiro. Movimentos sociais na América latina.Unisinos, 2008. Disponível em: http://www.projeto.unisinos.br/humanismo/al/mov_sociais.pdf. Acesso em: 23 jun. 2019.

RAMOS, Pedro. Propriedade, estrutura fundiária e desenvolvimento (rural).

Estudosavançados.v. 15, n.43. São Paulo, set./dez., 2001.

RONCHI, Maria Laura; WOLKMER, Antonio Carlos. Processos Constituintes LatinoAmericano e a Presença dos Movimentos Sociais no Brasil e na Bolívia. Revista Culturas Jurídicas, v.3, n.6, Niterói, dezembro, 2016.

SANTOS, Boaventura de Souza. Refundación del Estado em América Latina. Perspectiva desde uma epistemologia del Sur. La Paz: Plural, 2010.

SANTOS, Braulio de Magalhães. Plurinacionalidade, estado multicultural e direitos humanos. Espaço Jurídico, Joaçaba, v.13, n.1, p.31-52, jan. /jun. 2012.

SILVA, Thiago Henrique Costa; GONÇALVES NETO, João da Cruz. Novo constitucionalismo latino-americano: um constitucionalismo do futuro. Revista Brasileira de Filosofia do Direito, Brasília, v.3, n.1, p.60-81, jan./jun. 2017.

SOUZA, Marcel Soares de. Soberania e participação populares no Novo Constitucionalismo Latino-Americano: uma análise da Constituição venezuelana de 1999. Rabela, v.6, n.2, mai./ago. 2016.

TÁRREGA, Maria Cristina Vidotte Blanco; MAIA, Cláudio Lopes; FERREIRA, Adegmar José. Observatório da atuação do Poder Judiciário nos conflitos agrários decorrentes de ocupações de terra por movimentos sociais nos Estados do Pará, Mato Grosso, Goiás e Paraná (2003-2011). Goiânia: Faculdade de Direito, 2012.

VASCONCELOS, António Gomes. Desafios à reforma do poder judiciário na américa latina: justiça para os mercados e/ou para a sociedade. RIDB, n.2, 2014.

VITORINO, Diego. A base conceitual e a história do multiculturalismo, 2016. Disponível em: http://confrariando.com/a-base-conceitual-e-a-historia-do-multiculturalismo/. Acesso em: 28 jan. 2018.

WOLKMER, Antonio Carlos. Tendências contemporâneas do constitucionalismo latinoamericano: Estado plurinacional e pluralismo jurídico. Revista Pensar, Fortaleza, n.2, jul. /dez. 2011. 
WOLKMER, Antonio Carlos. Pluralismo Jurídico: fundamentos de uma nova cultura no direito. São Paulo: Alfa-Ômega, 2001. 